\title{
Development of the ATHENA mirror
}

Bavdaz, Marcos; Wille, Eric; Ayre, Mark; Ferreira, Ivo; Shortt, Brian; Fransen, Sebastiaan; Collon, Maximilien; Vacanti, Giuseppe; Barriere, Nicolas; Landgraf, Boris

Total number of authors:

26

Published in:

Space Telescopes and Instrumentation 2018: Ultraviolet to Gamma Ray

Link to article, DOI:

$10.1117 / 12.2313296$

Publication date:

2018

Document Version

Publisher's PDF, also known as Version of record

Link back to DTU Orbit

Citation (APA):

Bavdaz, M., Wille, E., Ayre, M., Ferreira, I., Shortt, B., Fransen, S., Collon, M., Vacanti, G., Barriere, N., Landgraf, B., Sforzini, J., Booysen, K., van Baren, C., Zuknik, K-H., Della Monica Ferreira, D., Massahi, S., Christensen, F., Krumrey, M., Muller, P., ... Seidel, A. (2018). Development of the ATHENA mirror. In Space Telescopes and Instrumentation 2018: Ultraviolet to Gamma Ray (Vol. 10699). [106990X] SPIE - International Society for Optical Engineering. https://doi.org/10.1117/12.2313296

\section{General rights}

Copyright and moral rights for the publications made accessible in the public portal are retained by the authors and/or other copyright owners and it is a condition of accessing publications that users recognise and abide by the legal requirements associated with these rights.

- Users may download and print one copy of any publication from the public portal for the purpose of private study or research.

- You may not further distribute the material or use it for any profit-making activity or commercial gain

- You may freely distribute the URL identifying the publication in the public portal 


\section{Development of the ATHENA mirror}

\section{Marcos Bavdaz, Eric Wille, Mark Ayre, Ivo Ferreira, Brian Shortt, et al.}

Marcos Bavdaz, Eric Wille, Mark Ayre, Ivo Ferreira, Brian Shortt, Sebastiaan Fransen, Maximilien Collon, Giuseppe Vacanti, Nicolas Barrière, Boris Landgraf, Jessica Sforzini, Karin Booysen, Coen van Baren, Karl-Heinz Zuknik, Desiree Della Monica Ferreira, Sonny Massahi, Finn Christensen, Michael Krumrey, Peter Müller, Vadim Burwitz, Giovanni Pareschi, Daniele Spiga, Giuseppe Valsecchi, Dervis Vernani, Paul Oliver, André Seidel, "Development of the ATHENA mirror," Proc. SPIE 10699, Space Telescopes and Instrumentation 2018: Ultraviolet to Gamma Ray, 106990X (6 July 2018); doi: 10.1117/12.2313296

Event: SPIE Astronomical Telescopes + Instrumentation, 2018, Austin, Texas, United States 


\title{
Development of the ATHENA Mirror
}

\author{
Marcos Bavdaz ${ }^{1}$, Eric Wille ${ }^{1}$, Mark Ayre ${ }^{1}$, Ivo Ferreira ${ }^{1}$, Brian Shortt ${ }^{1}$, Sebastiaan Fransen ${ }^{1}$, \\ Maximilien Collon ${ }^{2}$, Giuseppe Vacanti $^{2}$, Nicolas Barriere ${ }^{2}$, Boris Landgraf ${ }^{2}$, Jessica Sforzini ${ }^{2}$, Karin \\ Booysen $^{3}$, Coen van Baren ${ }^{4}$, Karl-Heinz Zuknik ${ }^{5}$, Desiree Della Monica Ferreira ${ }^{6}$, Sonny Massahi ${ }^{6}$, \\ Finn Christensen ${ }^{6}$, Michael Krumrey ${ }^{7}$, Peter Müller ${ }^{7}$, Vadim Burwitz ${ }^{8}$, Giovanni Pareschi ${ }^{9}$, Daniele \\ Spiga $^{9}$, Giuseppe Valsecchi ${ }^{10}$, Dervis Vernani ${ }^{11}$, Paul Oliver ${ }^{12}$, André Seidel ${ }^{13}$ \\ ${ }^{1}$ European Space Agency, ESTEC, Keplerlaan 1, PO Box 299, NL-2200 AG Noordwijk, The Netherlands \\ ${ }^{2}$ cosine, Oosteinde 36, NL-2361 HE Warmond, The Netherlands \\ ${ }^{3}$ Micronit Microfluidics B.V., Colosseum 15, NL-7521 PV Enschede, The Netherlands \\ ${ }^{4}$ SRON, Sorbonnelaan 2, NL-3584 CA Utrecht, The Netherlands \\ ${ }^{5}$ OHB System AG, Manfred-Fuchs-Straße 1, 82234 Weßling, Germany \\ ${ }^{6}$ DTU Space, Elektrovej 328, 2800 Kgs Lyngby, Denmark \\ 7 Physikalisch-Technische Bundesanstalt (PTB), Abbestr. 2-12, D-10587 Berlin, Germany \\ 8 MPI für extraterrestrische Physik, Giessenbachstrasse, D-85748 Garching, Germany \\ ${ }^{9}$ INAF Osservatorio Astronomico di Brera, Via E. Bianchi 46 I- 23807, Merate (LC), Italy \\ ${ }^{10}$ Media Lario S.r.l., Località Pascolo, I-23842 Bosisio Parini (LC), Italy \\ ${ }^{11}$ Thales Alenia Space Switzerland Ltd, Schaffhauserstrasse 580, 8052 Zürich, Switzerland \\ 12 Teledyne Imaging, 106 Waterhouse Lane, Chelmsford, Essex CM1 2QU, England \\ ${ }^{13}$ Fraunhofer Institute for Material and Beam Technology, Winterbergstrasse 28, D-01277 Dresden, Germany
}

\begin{abstract}
The development of the X-ray optics for ATHENA (Advanced Telescope for High ENergy Astrophysics)[1-4], the selected second large class mission in the ESA Science Programme, is progressing further, in parallel with the payload preparation and the system level studies.
\end{abstract}

The optics technology is based on the Silicon Pore Optics (SPO) [5-48], which utilises the excellent material properties of Silicon and benefits from the extensive investments made in the semiconductor industry. With its pore geometry the SPO is intrinsically very robust and permits the use of very thin mirrors while achieving good angular resolution. In consequence, the specific mass of the resultant ATHENA optics is very low compared to other technologies, and suitable to cope with the imposed environmental requirements.

Further technology developments preparing the ATHENA optics are ongoing, addressing additive manufacturing of the telescope structure, the integration and alignment of the mirror assembly, numerical simulators, coating optimisations, metrology, test facilities, studies of proton reflections and meteorite impacts, etc. A detailed Technology Development Plan was elaborated and is regularly being updated, reflecting the progress and the mission evolution. The required series production and integration of the many hundred mirror modules constituting the ATHENA telescope optics is an important consideration and a leading element in the technology development. The developments are guided by ESA, implemented in industry and supported by research institutions.

The many ongoing SPO technology development activities aim at demonstrating the readiness of the optics technology at the review deciding the adoption of ATHENA onto the ESA Science flight programme, currently expected for 2021. Technology readiness levels of 5/6 have to be demonstrated for all critical elements, but also the compliance to cost and schedule constraints for the mission.

Keywords: X-ray optics, X-ray astronomy, ATHENA, Silicon Pore Optics, X-ray telescopes, X-ray testing, Technology preparation, Additive manufacturing

Space Telescopes and Instrumentation 2018: Ultraviolet to Gamma Ray, edited by Jan-Willem A. den Herder, Shouleh Nikzad, Kazuhiro Nakazawa, Proc. of SPIE Vol. 10699, 106990X · C 2018 SPIE CCC code: $0277-786 X / 18 / \$ 18 \cdot$ doi: $10.1117 / 12.2313296$ 


\section{MISSION ADOPTION REQUIREMENTS AND TECHNOLOGY PLAN}

ESA Science missions are studied extensively after their selection from proposals submitted by the European science community. These studies are performed in industry, with at least two consortia working in competition, to mature the mission concept and design to a level, which is adequate to reliably determine the expected mission implementation cost, schedule and performance. The results of these Phase A studies conclude with the Preliminary Requirements Review (PRR), and B1 studies are at the center of the Mission Adoption Review (MAR), which for ATHENA is expected to occur in the year 2021. Once adopted on the flight manifest of the ESA Science Programme, the mission enters its implementation phase with a solid schedule and launch slot.

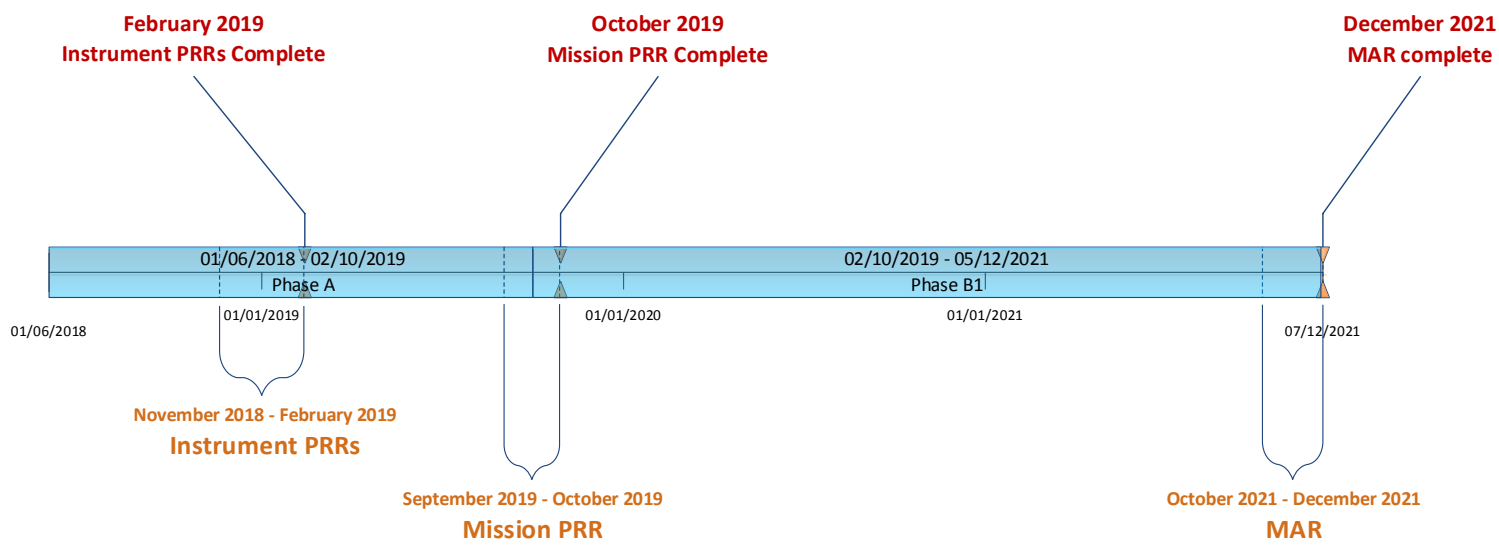

Figure 1: The ATHENA timeline until mission adoption, expected in 2021. The Preliminary Requirements review (PRR) of the instruments is followed by the system level PRR, which effectively finalises the mission formulation, and completes the phase A studies. Phase B1 is closed with the Mission Adoption Review (MAR), in which all elements of the mission are reviewed, including the payload, and where the technology readiness has to be demonstrated.

The payload of ESA Science missions is often provided by Member State consortia, as are the two focal plane instruments of ATHENA, and is nationally funded, studied and developed in parallel to the system studies. These payload study results are equally scrutinised in the MAR.

The third element of the mission preparation before the adoption is the preparation of the required critical technologies. In order to reduce the risks during the mission implementation phase, each single technology required for the mission, be it on the spacecraft or its payload, must demonstrate a Technology Readiness Level (TRL) of 5/6, following ISO 16290 [49]. This means that each technology has to demonstrate the required performance and compatibility with the relevant environment, including survival of launch loads and operations in space. The technologies are subject to Technology Readiness Assessments (TRA), which form an integral part of the MAR.

The ATHENA optics is based on the novel Silicon Pore Optics (SPO), and many development activities are running or planned, targeting demonstration of the required TRL. A detailed Technology Development Plan (TDP) is required to coordinate these activities, and this TDP has to be regularly updated, to reflect the mission evolution and the technology progress. This ATHENA optics TDP (figure 2) is linked to the ATHENA reviews, and is funded by several ESA programmes. The activities are implemented in industry and research entities, and are closely followed by ESA experts.

The main development thrust regards the SPO mirror modules, optimizing the performance, proving the environmental compatibility and working on several mirror module types spanning the radial extent of the ATHENA optics (first four lines of figure 2). These development lines will culminate in the production of Engineering and Qualification Models (EQM) of the ATHENA mirror modules. A pre-requisite for such work is the availability of the required components, in reliable quality and sufficient quantities. 
A large number of mirror plates is required already in the development phase, and consequently a second mirror plate supply chain is being implemented. A steady and robust supply of high quality mirror plates will be of particular importance in the Flight Model (FM) implementation phase, therefore a structured and gradual increase of the production capacity is essential. Similarly, the planning of the FM mirror module production facilities has to be concluded before the MAR, and a dedicated activity is planned to be started after the PRR. A further activity focuses on the optimisation of the coatings to be applied to the reflecting surfaces.

About 678 mirror modules will have to be integrated and co-aligned onto the optical bench of the Mirror Assembly Module (MAM) of ATHENA. This is a demanding task of the mission implementation phase, which will have to be completed in about two years. Two competitive activities have therefore been initiated in 2015, targeting the demonstration of two different technical approaches for co-aligning and mounting the mirror modules to the optical bench. Both activities have recently been concluded, both achieving not only the requirements, but also the goals (see later for more details). After the ATHENA PRR a follow-on activity is planned, which will produce the ATHENA Mirror Assembly (MA) demonstrator, consisting of a 60 degree segment of the MAM structure, populated by mirror modules of several radii.

The MAM structure has a complex geometry and will be manufactured of monolithic titanium, for reasons of strength and thermal expansion properties. Conventional subtractive machining of such a large and complex item is challenging and may exceed current capabilities. For that reason a novel approach is being demonstrated ("ALM Mirror Structure"), based on hybrid manufacturing, whereby titanium powder is fused using powerful lasers, adding material and forming the required structure. In a second step, subtractive machining is used to achieve the required geometrical tolerances.

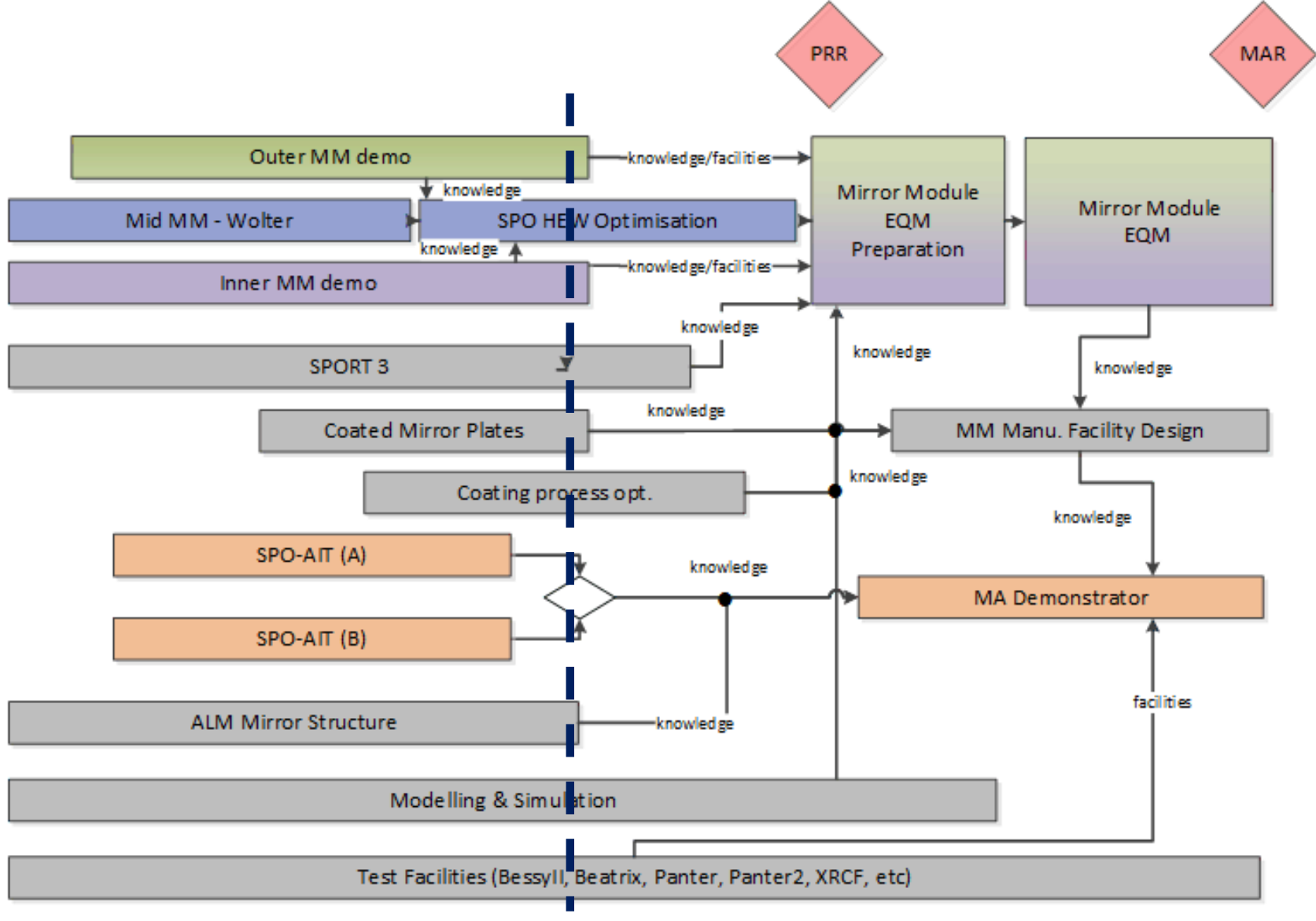

Figure 2: The ATHENA optics Technology Development Plan (TDP) ensures that all aspects of the ATHENA optics are covered with dedicated focused technology activities, which are properly phased and coordinated. The planning is consistent with the ATHENA mission level schedule and milestones, and evolves the ATHENA optics technology to the level required for the MAR. The current status is marked by black dashed line. 
Modelling and simulation activities complement the hardware activities.

The testing of the performance of the ATHENA optics requires new facilities, which have significant lead times and which represent substantial investments. The timely study and design of these facilities is mandatory for the smooth implementation of the ATHENA mission. Some of these facilities are required for the assembly of the mirror modules using synchrotron radiation, others are required to characterise mirror modules for acceptance testing, and to perform the verification and calibration of the complete ATHENA X-ray optics.

In the TRAs, the TRL 5 and higher are assessed to a specific mission environment, ATHENA in our case, and therefore the system studies are tightly coupled to the technology developments. Although industrial capacities are formally not taken into account in the TRL, these are an additional important factor considered in the MAR, and requires adequate actions well in advance of the MAR. Equally important are the quality and product assurance aspects (PA/QA) for the flight production, which require due attention in the technology preparation.

\section{PROGRAMMATIC FACTORS}

The ATHENA mission requires the largest X-ray optics ever built. In order to provide the effective area required to achieve the demanding scientific goals $\left(1.4 \mathrm{~m}^{2}\right.$ at $\left.1 \mathrm{keV}\right)$, the ATHENA telescope optics needs to cover a circular area of about $2.5 \mathrm{~m}$ diameter. This mirror assembly consists of about 678 mirror modules, which have to be accurately coaligned on a stiff and stable optical bench. The whole mirror assembly is articulated, and the detector instrument in use is selected by tilting the mirror assembly. This is achieved with the implementation of a hexapod supporting the optics (see figure 3).

As part of the MAR, the programmatic compliance of the mission with the boundary conditions is scrutinised. This includes the review of compliance to the cost and schedule constraints for the ATHENA optics implementation, which is equally imperative as the achievement of the angular resolution and effective area performance.

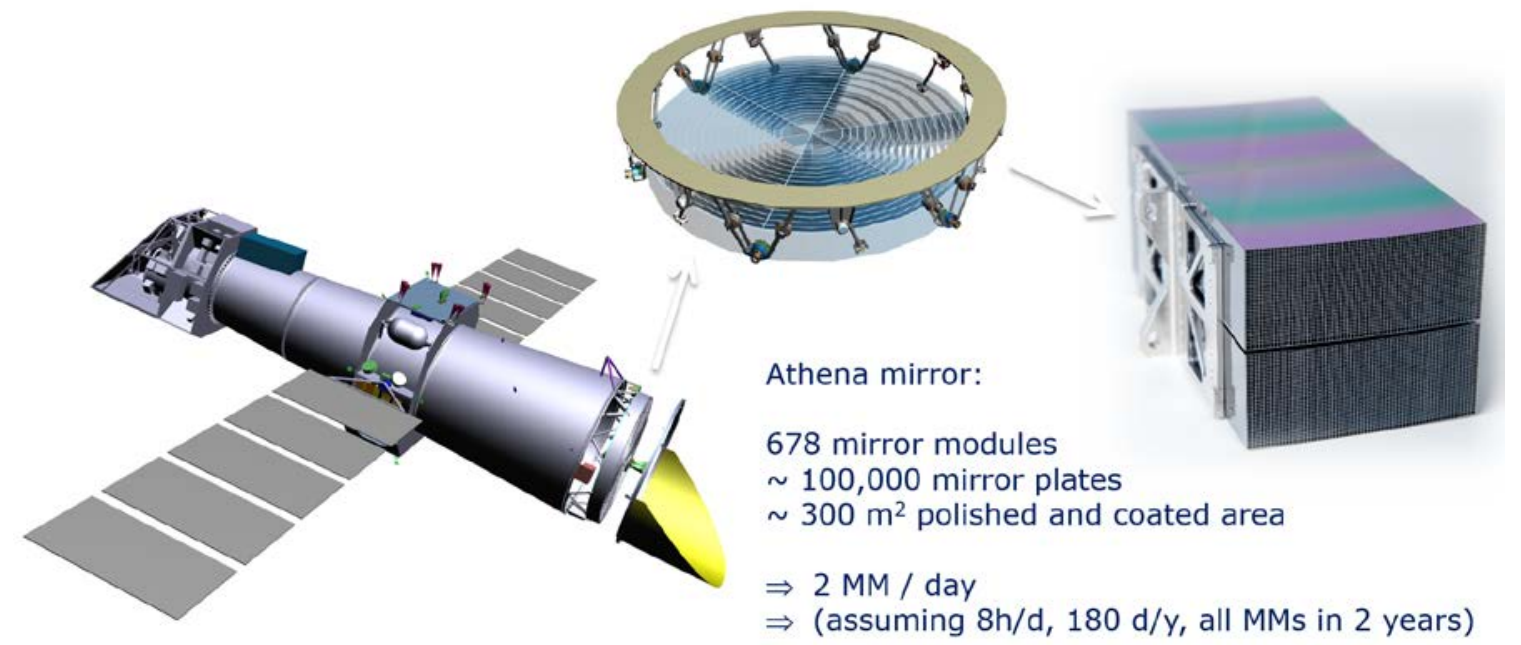

Figure 3: ATHENA requires the largest X-ray optics ever made. The effective area has to be far larger than any preceding mission, without compromising the angular resolution. At the same time the mass and cost envelopes have to remain very comparable to those of the most powerful current missions, Chandra [50] and Newton [51]. With the introduction of the modular Silicon Pore Optics (SPO) technology these conflicting requirements can be met. In the flight production phase about 2 mirror modules have to be produced and integrated each day. 
A key element of the SPO technology for ATHENA is the modularity of the optics. All 678 mirror modules of the ATHENA telescope have to be accurately co-aligned on the MAM structure. The large ATHENA mirror, despite its large size, requires only relative compact X-ray optics production facilities to produce the mirror modules. The series production of the mirror modules is very cost effective, relying on a high degree of automation. The production equipment is largely procured from the microelectronics industry, where significant investments have been made in the development of efficient and reliable tools. Even the mirror plate material, made of monocrystalline silicon, finished with super-polished surfaces, is procured in the form of fab-grade $300 \mathrm{~mm}$ silicon wafers. The ATHENA mirror plates can therefore be produced in large quantities at a low cost, with a uniformly high quality.

The ATHENA flight optics production schedule is tight, allocating two years for the production and integration of 678 mirror modules. On average two mirror modules will have to be produced and installed each working day. This could not be achieved, if not considered from the on-set of the SPO development. The TDP is designed to demonstrate not only the performance and environmental compatibility of the ATHENA optics, but also to pave the way for the cost effective and efficient implementation of the ATHENA optics. The development of the production equipment is already occurring now, ranging from the mirror plate production, stacking robots, module assembly facilities to the concept validation for the MAM population with optical modules.

\section{MIRROR MODULE PRODUCTION}

All steps of the later flight model optics production are currently being exercised to improve the quality and therefore angular resolution, and to prepare for mass production. As part of the phase A activities, the production of the mirror plates and stacks is being transferred from development engineers to trained operators. The production of the mirror plates uses industrial equipment and facilities (see figure 4 left), and the capacity is being continuously ramped up. The mission implementation phase QA/PA requirements are being considered already now, in phase A: e.g. mirror plates are individually labelled (see figure 4 right) by laser engraving, tracing them back to the wafers. In the mirror plate stacking process all parameters are being carefully logged, and the production processes and procedures documented in detail. To match the higher plate production rate, also the subsequent processes of coating and stacking have to be sped up. A mirror plate can be mounted (stacked) in 13 min now, down from 45 minutes a year ago, en route to the 6 minutes required in the mission implementation phase.

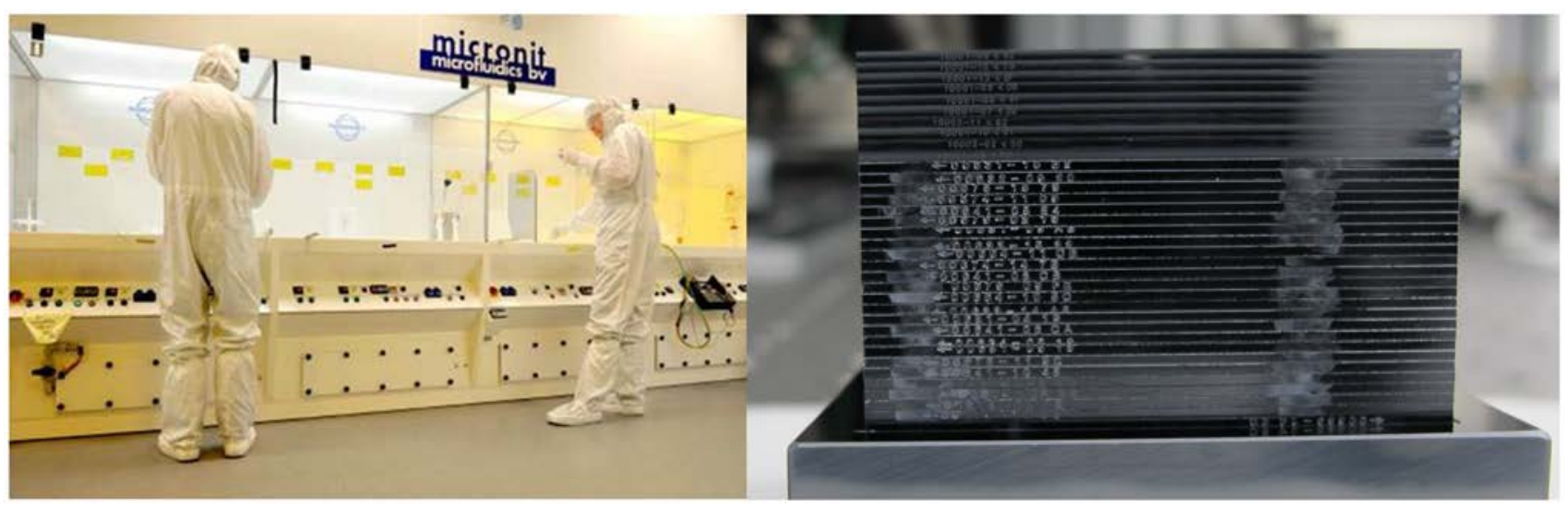

Figure 4: SPO mirror plates, already during the SPO development phase, being produced in industrial facilities (left. Each mirror plate is identified with a unique laser-engraved code, meeting the quality assurance requirements expected for the flight programme (right). Teledyne Imaging is being developed as a second, independent, mirror plate supplier, providing a robust supply chain for the future flight model implementation. Note in the right figure, that the mirror plates of the two suppliers are compatible with each other, being able to be stacked and bonded to each other (10 Teledyne Imaging plates bonded to 25 Micronit plates). 
Equally important is the uniform and reproducible coating of the mirror plates. Building on the work done for the most demanding recent mission in this respect, NuSTAR [52], the coating process for ATHENA has to be further evolved, to comply with the strict quality and mass production requirements. A new industrial coating machine is being commissioned, with a capacity to coat in two years all plates required for ATHENA (see figure 5 left). The machine is automated and allows the plasma cleaning and the application of all required coatings of many mirror plates in a single process. A second machine will be later required for redundancy. The coating recipe, optimised for ATHENA, is being developed by DTU in a dedicated activity. The principle of stacking coated plates has already been demonstrated. These activities will allow the production of more coated mirror stacks on all three representative radii, such that coated mirror modules compliant with the ATHENA requirements can be demonstrated at the MAR.
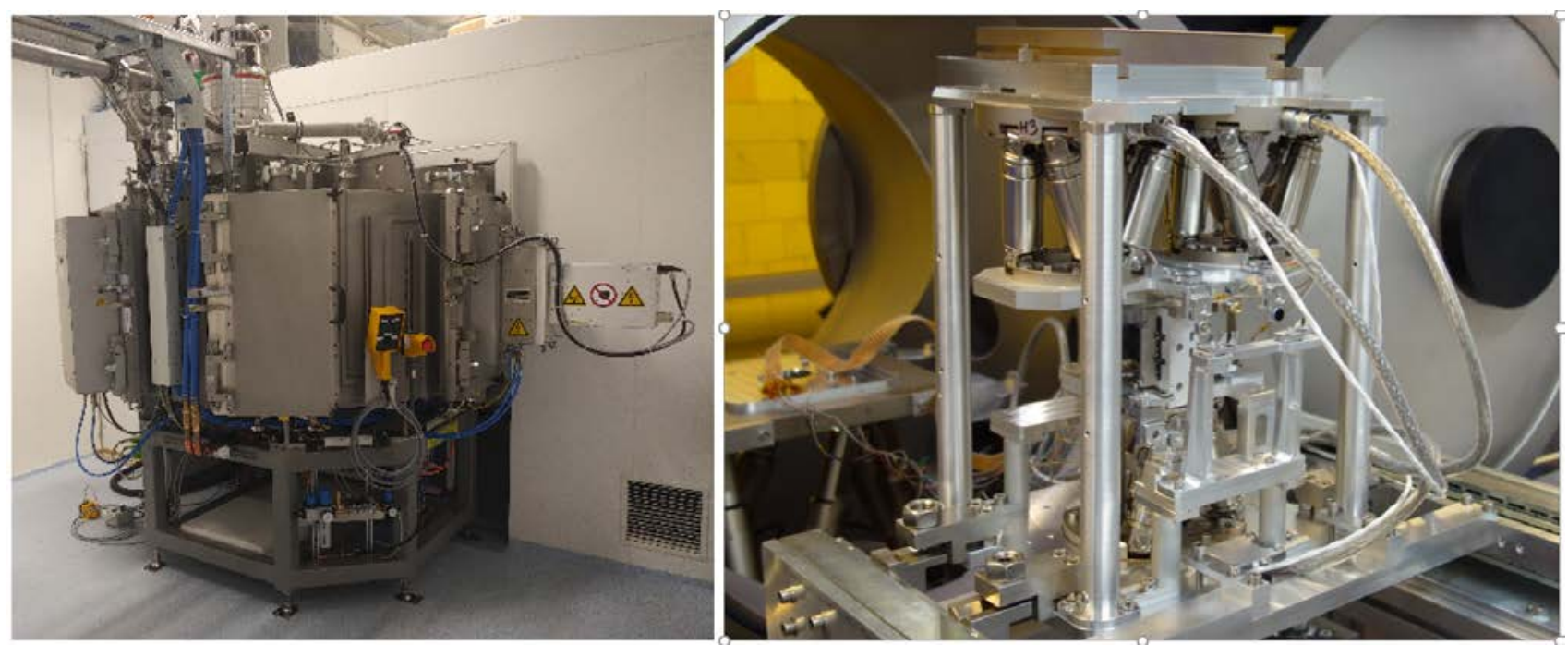

Figure 5: Tools are very important, preparing the way to the implementation phase. The coating and stacking of the mirror plates requires a high level of automation, in order to satisfy the programmatic requirements of the ATHENA mission. An industrial coating machine is being commissioned at the premises of the main SPO contractor, cosine (left). The assembly of the mirror plate stacks into mirror modules is a precision operation, taking place at a synchrotron facility. A dedicated 24 DOF assembly tool was developed and installed at the XPBF 2.0 beamline at the BESSY II facility in Berlin, Germany, consisting of 3 vacuum compatible hexapods, mounted on the beamline optics chamber hexapod (right).

Once the mirror plates are mounted, assembled to stacks of 35 mirror plates, the mirror modules have to be assembled, accurately co-aligning four stacks to form a mirror module. A synchrotron pencil beam is used in this process, employing a 24 degree of freedom (DOF) assembly tool operating in vacuum (see figure 5 right).

The completed mirror modules (see figure 6 left) are compact X-ray optics units, which are robust and easy to handle. They provide three hard points, which are used to mount the mirror modules to a structure using an isostatic mount formed by three dowel pins. The mirror module shown is one of four identical units built to demonstrate their integration into the MAM structure.

The mirror modules are characterised in two independent X-ray facilities, operated by two independent teams: the the Xray Parallel Beam Facility (XPBF 2.0) in the laboratory of the Physikalisch-Technische Bundesanstalt (PTB) at the BESSY II synchrotron radiation facility in Berlin, and the PANTER long beam facility of the Max-Planck-Institut für Extra-terrestrische Physik located near Munich [53-57]. 

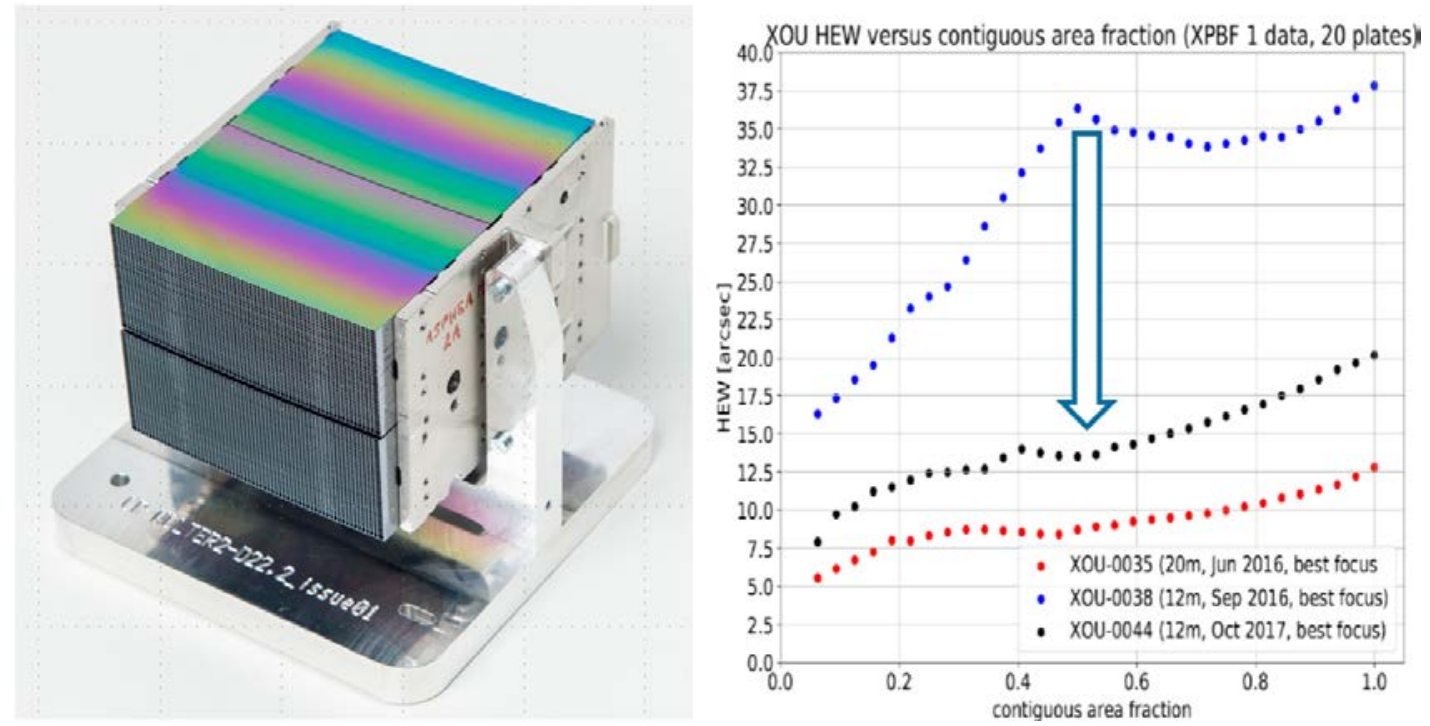

Figure 6: Several SPO mirror modules (MM) have been produced, with improving performance. In 2016 the focal length of the optics development programme was changed from $20 \mathrm{~m}$ to $12 \mathrm{~m}$, as required by ATHENA, and the production equipment had to be modified accordingly. The left image shows one of the MMs produced for the demonstration of the MM integration onto the ATHENA mirror structure. On the right the improvement of the imaging performance of the MMs is illustrated, plotting the Half Energy Width (HEW) as function of the contiguous area fraction. Such a plot has been developed for the purpose of explaining the measured performance of the optics in flight representative configuration, in a form suitable for different communities. The contiguous area fraction is defined as the fraction of the total MM optical face area, which extends over many plates of the MM, but is laterally limited by baffles. This graph also indicates the opportunity offered by the SPO technology, to trade effective area for an improved angular resolution. The important priority of the current optics developments is the improvement of the performance of the optics towards the lateral edges of the mirror module, i.e. increasing the good performance observed on the left side of the graph, until the angular resolution required by ATHENA is achieved over the complete mirror area.

The improvement in X-ray imaging performance is evident in the right plot of figure 6. The Half Energy Width (HEW) is shown as function of the contiguous area fraction, which is defined as the fraction of the mirror module optical face area, which is collecting radiation. The remainder of the optical area is covered by aperture stops limiting the lateral size of the accepted beam. Due to the modularity and geometry of the SPO mirror modules, it becomes possible to trade effective area for improved angular resolution. Note that any decision on this trade can be taken very late, maximizing the flexibility of the ATHENA optics design.

The angular resolution has improved by more than a factor of 2 from the first $12 \mathrm{~m}$ focal length module produced late 2016, to the small series of mirror modules produced for the integration demonstration activities about a year later. Note that only three months of that year were available for HEW improvements. The performance is approaching the results obtained with the preceding $20 \mathrm{~m}$ focal length modules, and is currently being optimised further. This graph represents the results of the first iteration, and the current work is focused on the continued improvement of the angular resolution of the SPO optics, until the requirements of ATHENA are achieved.

As indicated in the TDP (figure 2), work targeting the inner-most and outer-most radii of the ATHENA mirror has also started. These activities were initiated once the first middle radius mirror modules have been made and the SPO technology has been validated, and address the differences and specific challenges posed by these radii. These activities have already demonstrated the production of the required mirror plates, and are currently optimising the production of mirror stacks, before progressing to mirror modules. The innermost mirror modules feature longer mirror plates, which are curved to a much smaller radius (see figure 7, left). Such mirror stacks have been produced and demonstrate the stability of such stacks with $250 \mathrm{~mm}$ radius. The work on these mirror modules also investigates the influence of the rib spacing and mirror membrane thickness. The larger pores (rib pitch is $2.3 \mathrm{~mm}$ instead of the normal $1 \mathrm{~mm}$ ) of these modules increase the open area fraction and the off-axis effective area provided by the optics. 

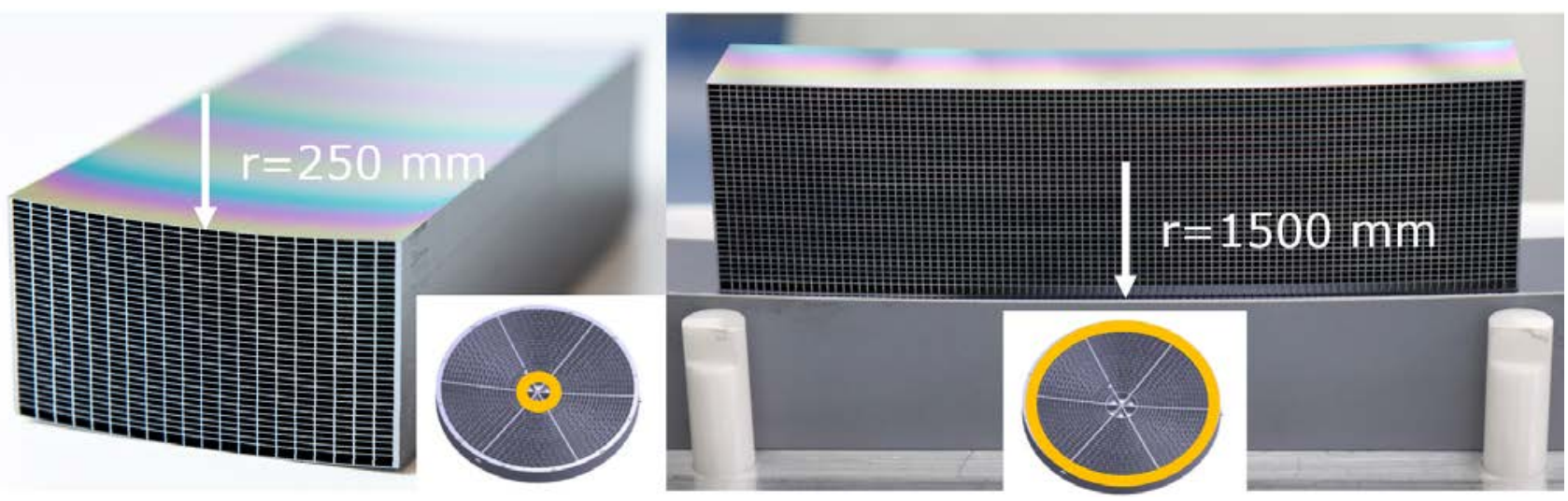

Figure 7: Work is progressing also on the innermost (left, with $250 \mathrm{~mm}$ innermost radius) and outermost mirror modules (with an outer radius of $1500 \mathrm{~mm}$, right). Note that the rib spacing is increased to $2.3 \mathrm{~mm}$ for the innermost MM.

The outermost mirror modules, on the other hand, have other challenges, and are being demonstrated for a radius of 1500 $\mathrm{mm}$ (corresponding to an ATHENA mirror with 20 rows of mirror modules). The mirror plates are very short, about 20 $\mathrm{mm}$ only, and edge effects have to be particularly well controlled. These outer mirror modules explore larger stack widths (102 mm), which also increases the packing density and therefore the effective area of the optics.

Special test equipment is in place, reproducing the loads expected to be experienced by the optics of the ATHENA mission (figure 8). In particular the shock loads, generated by the release of the clamp-band when separating the spacecraft from the launcher, are important to be accurately generated, simulating the required shock response spectrum simultaneously in all three axes. The expected levels reach $350 \mathrm{~g}$ on mirror module level [58]. High speed cameras and accelerometers are used to study and to improve on the properties of mirror modules and their components.
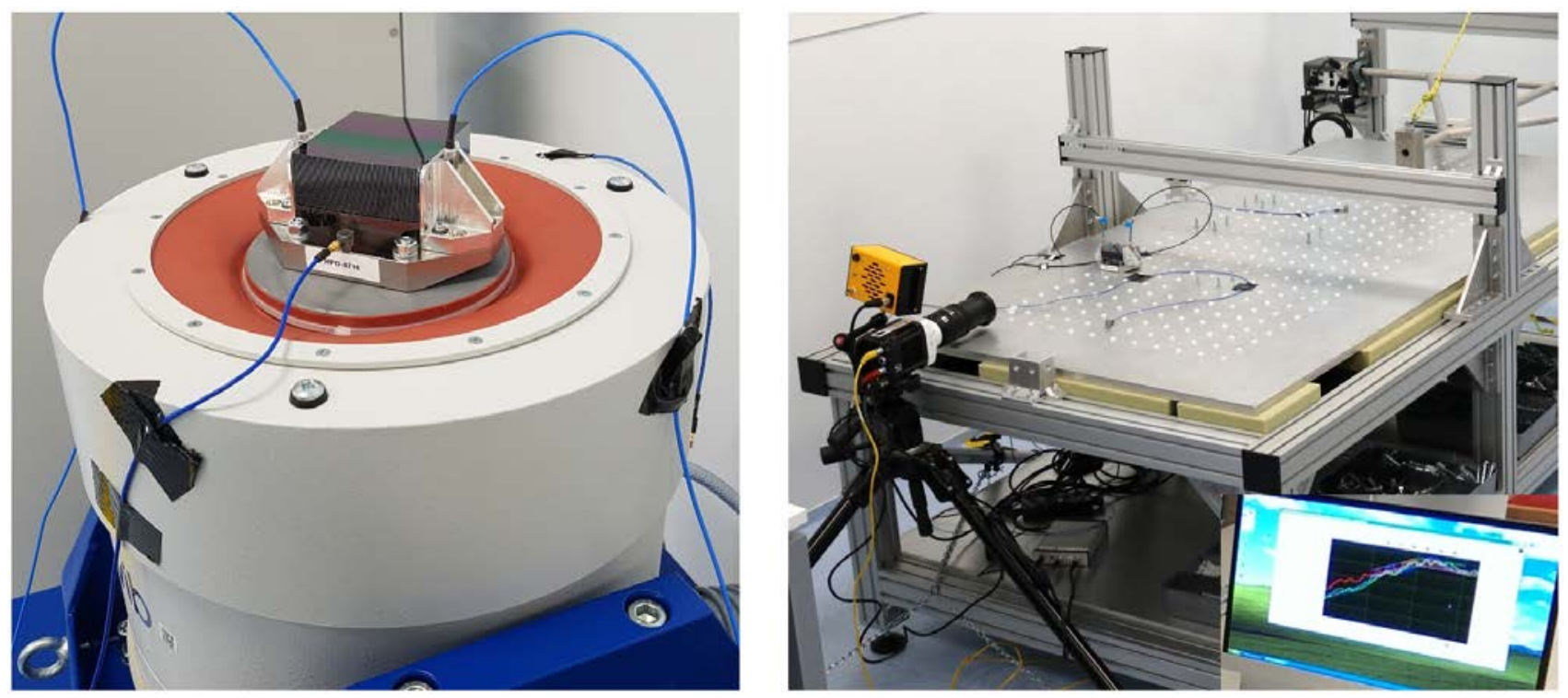

Figure 8: Special test equipment was procured and developed for testing SPO stacks and modules. The shaker (left image) is shown testing a mirror stack, in a series exploring the options for increasing the strength by annealing. The shock table (right image) was tuned to reproduce the expected shock spectrum experienced by the SPO MMs during the launcher clamp band release. In a single test all three axes $(\mathrm{X}, \mathrm{Y}, \mathrm{Z})$ can be tested. The instrumentation of the shock table includes a high speed video camera (on tripod) taking 10000 frames per second. 


\section{MIRROR ASSEMBLY}

The precise co-alignment of the mirror modules on the optical bench of the Mirror Assembly Module is essential for the performance of the ATHENA mirror. The respective error budget allocation is small, about 1.1 arcseconds (to be added in quadrature), and the integration of the mirror modules into the MAM has to be cost effective and fast. The integration equipment must be capable of integrating two mirror modules each working day in the flight production phase, and must be demonstrated before the MAR. Two technology development activities were implemented for this purpose, executed by two independent industrial consortia.

The first team, led by Medialario, employed UV light to align the mirror modules, and modified the still existing equipment originally used to assemble the optics for the XMM/Newton mission (figure 9). Two mirror modules have been integrated into a representative sub-assembly of the MAM, using a flight representative dowel pin kinematic mount. The co-alignment accuracy was measured under X-ray illumination in the PANTER facility, confirming that the mirror modules were aligned to better than 0.7 arcseconds. In the following it was also demonstrated, that a mirror module can be removed again from the MAM, and re-installed, without compromising the adjacent mirror modules.
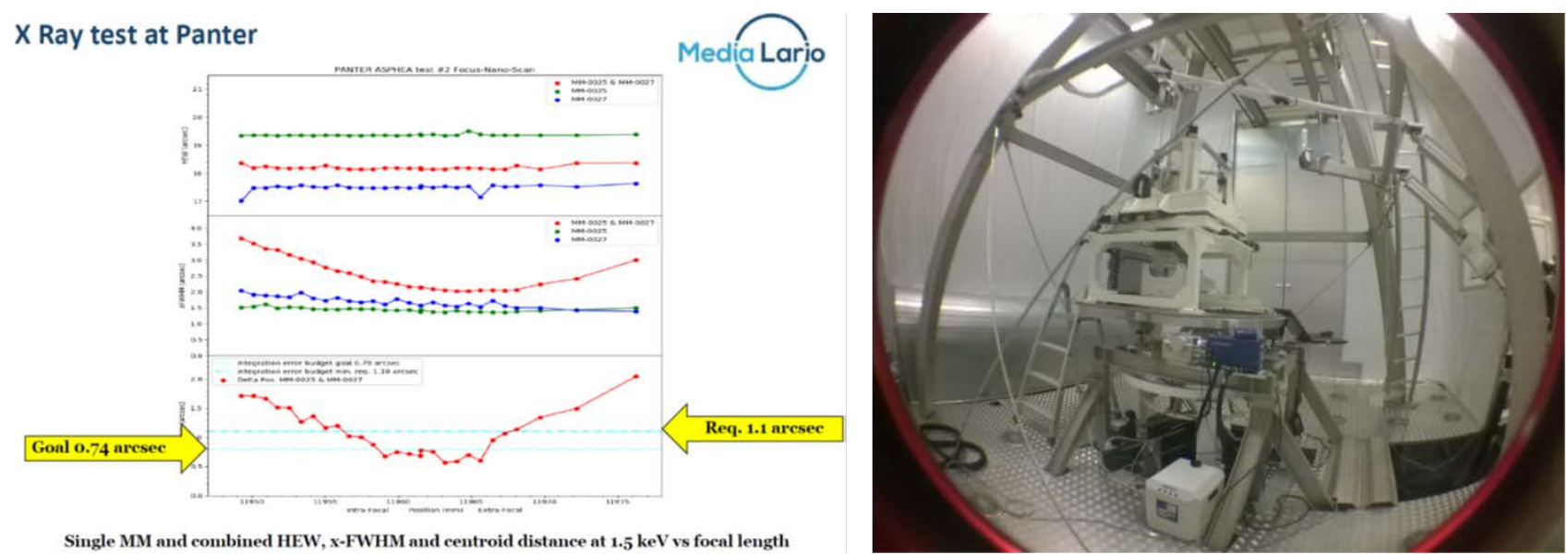

Figure 9: Mirror modules have been co-aligned using a collimated UV beam in a modified facility originally used to assemble the optics of XMM/Newton (right image). A co-alignment accuracy better than required for ATHENA was achieved, as illustrated with the results obtained at the PANTER X-ray facility near Munich (left image). Two MMs were installed in a flight representative configuration into a titanium structure. Additionally it was successfully demonstrated, that a MM can be removed again, and replaced with a new co-aligned MM.

The second team, led by TAS-Switzerland, successfully demonstrated two more approaches. One relies on the accurate determination of the X-ray optical axis of the mirror module following its assembly, employing synchrotron radiation, and the consequent referencing of this axis to fiducials attached to the mirror module. These fiducials are later used together with laser-trackers and theodolites to accurately align the mirror modules on the MAM structure. Again, the coalignment of the two mirror modules was measured at the PANTER facility, confirming the achievement of the alignment goals. The other approach to align the mirror modules used the X-ray illumination at the PANTER facility to directly observe and align the foci of the two mirror modules (figure 10).

One of these mirror module alignment methods will be soon selected, following a detailed review of the results, and used to produce the ATHENA Mirror Assembly (MA) demonstrator. 

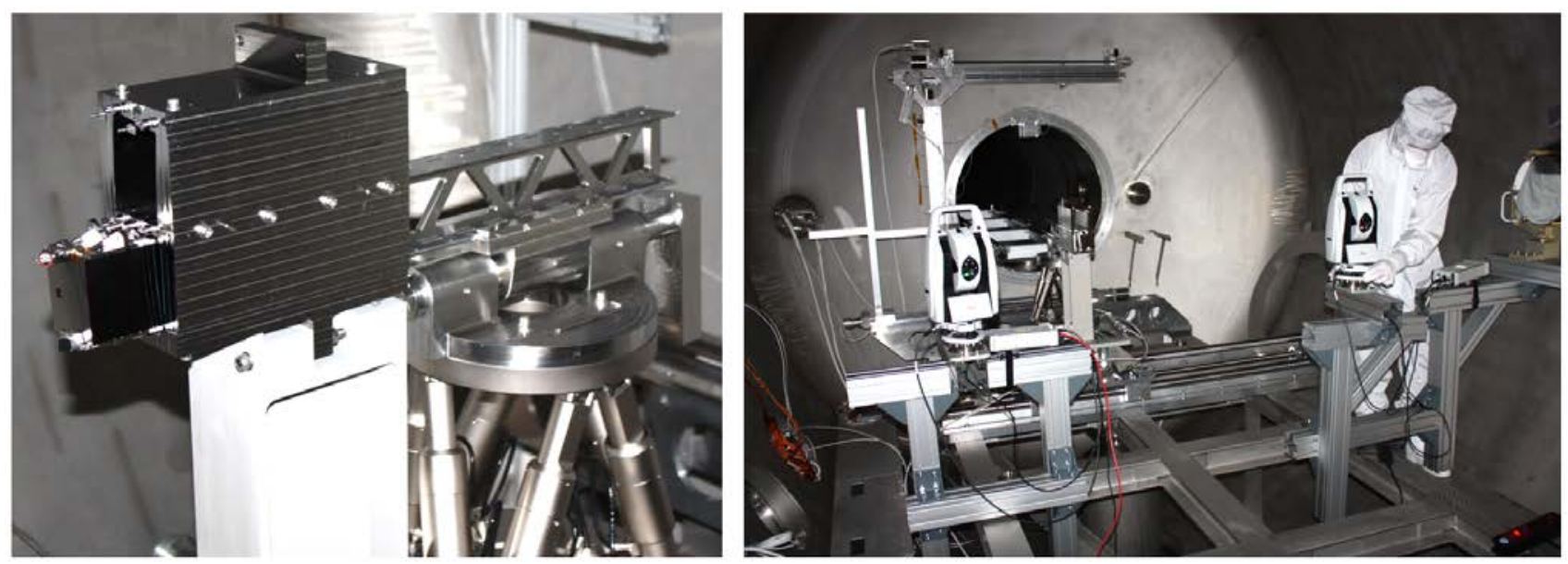

Figure 10: An independent industrial consortium led by TAS-CH demonstrated that the MMs can also be co-aligned to the specification of ATHENA using indirect metrology. The indirect metrology approach relies on referencing of fiducials on the MM to the X-ray optical axis using synchrotron radiation after the assembly of the MM. Modern optical metrology tools like laser trackers are a key element of this approach. The left image shows the titanium structure with one MM being installed, using a hexapod-mounted grabber. The set-up at the PANTER facility is shown in the right image, where the co-aligned was verified to exceed the requirements. In addition, also the integration using direct X-ray metrology was demonstrated.

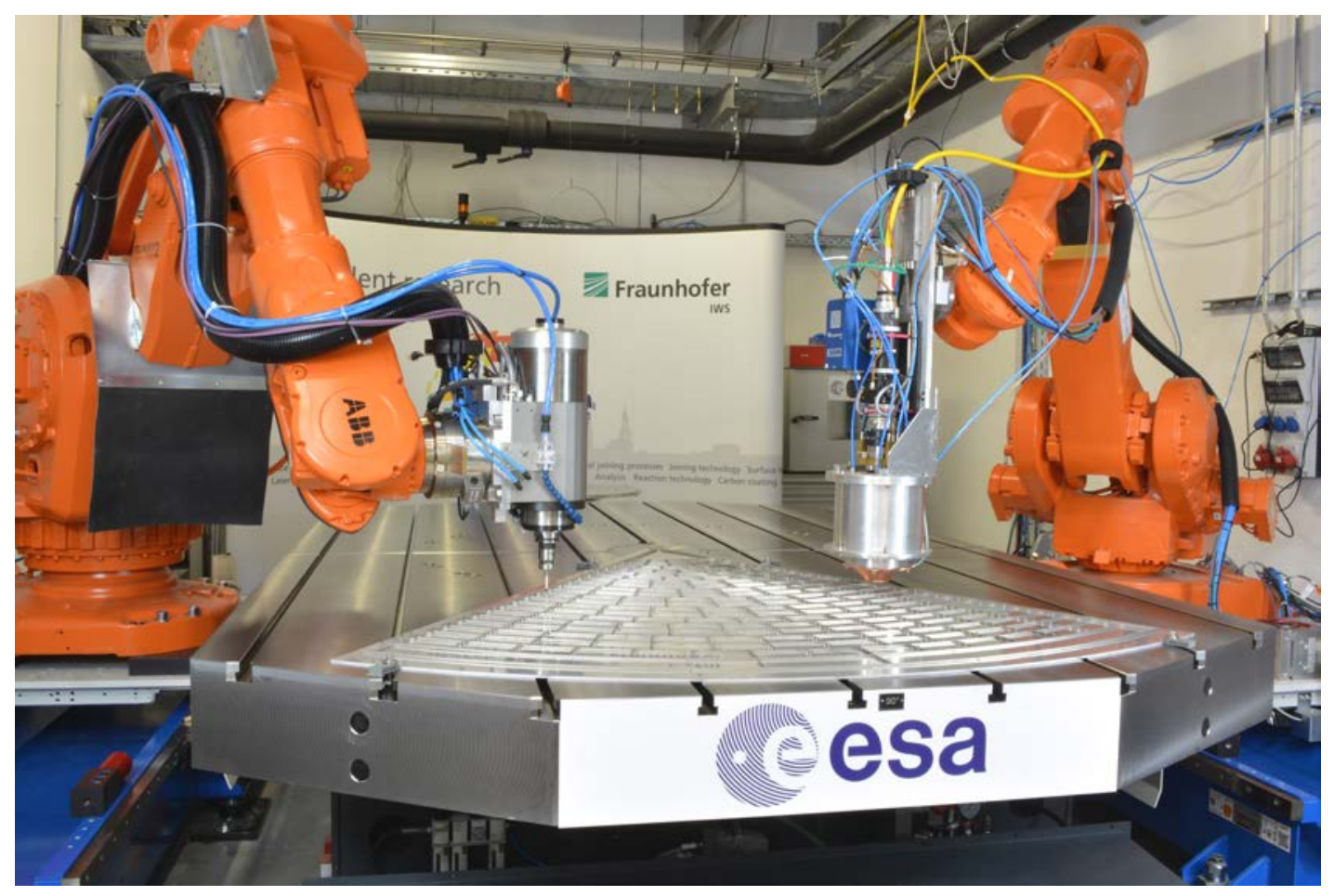

Figure 11: A novel titanium hybrid manufacturing facility is being set up to demonstrate the production of the monolithic titanium structure, which is baselined as the core of the ATHENA Mirror Assembly Module (MAM). This structure necessarily has a very complex geometry, since it has to accommodate the $678 \mathrm{MMs}$, and keep them accurately aligned from production over the launch sequence to the operation in space for the lifetime of the mission. Being a very large structure (2.5 to $3 \mathrm{~m}$ diameter, and about 300 $\mathrm{mm}$ high), it is difficult to manufacture with traditional (subtractive) machining. High precision industrial robots are used to position the tools over the high accuracy rotating platform. The right robot is used to add titanium material, using high power 
lasers with a proprietary sensor set and control loop. The left robot is used for the subtractive machining following the additive step (therefore hybrid manufacturing). The left robot also serves as a metrology tool.

The production of the MAM core structure, into which the 678 mirror modules are installed, is non-trivial, being made of titanium with a size of 2.5 to 3 meters in diameter and about $300 \mathrm{~mm}$ high. The geometry of the structure is very complex, providing a dedicated pocket for each of the mirror modules, and accommodating the thermal control system, whilst maximising the mirror module packing efficiency and minimizing the geometric obstruction. An activity to demonstrate the production of such a structure by hybrid manufacturing is currently running. A facility is being commissioned, where titanium additive manufacturing is combined with subtractive machining (figure 11). Employing precision industrial robots and a rotating table, structures up to more than $3 \mathrm{~m}$ in diameter can be produced.

\section{X-RAY METROLOGY, VERIFICATION AND CALIBRATION}

Dedicated X-ray metrology, verification and calibration facilities are required for the assembly and characterisation of the mirror modules, and the verification and calibration of the complete ATHENA optics. Recently a new beamline (XPBF 2.0) was completed [56], where mirror modules of $12 \mathrm{~m}$ focal length can be assembled, using a collimated synchrotron radiation beam (figure 12). This beamline is located in the laboratory of the Physikalisch-Technische Bundesanstalt (PTB) at the BESSY II facility in Berlin. A collimated beam of $50 \mu \mathrm{m}$ x $50 \mu \mathrm{m}$ to $5 \mathrm{~mm}$ x $5 \mathrm{~mm}$ in size can be generated, and the optics sample can be positioned to $\mu \mathrm{m}$ and arcsecond accuracy, employing autocollimators and a precision hexapod. A peltier-cooled CCD camera at $12 \mathrm{~m}$ distance is used to measure the image produced by the optics under test.

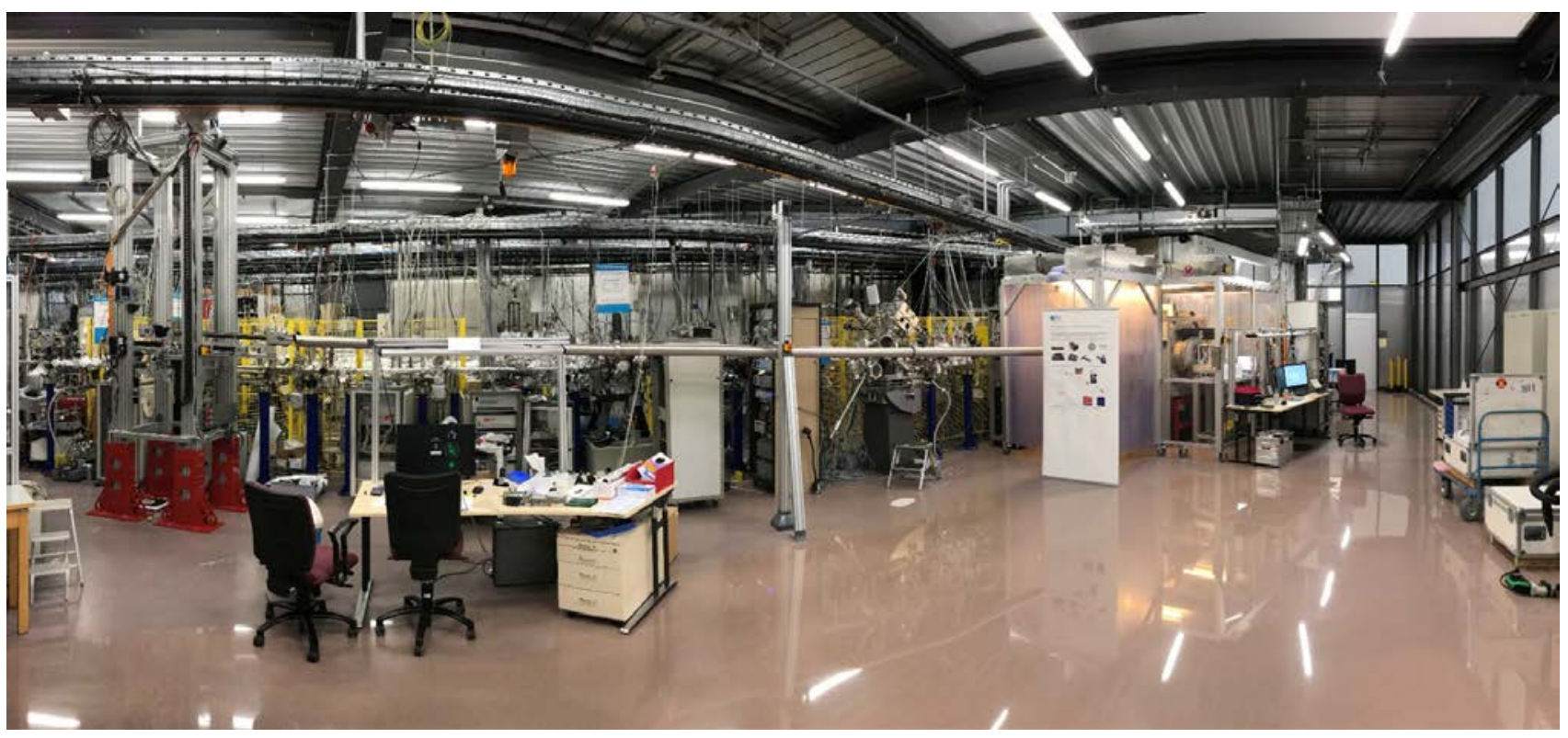

Figure 12: The MMs are assembled and characterised using synchrotron radiation metrology. The ATHENA beamline was completed and commissioned in the laboratory of the Physikalisch Technische Bundesanstalt (PTB) at the BESSY II facility in Berlin. The clean tent protecting the optics vacuum chamber is visible in the right part of the image, connected with a vacuum beamline to the focal plane assembly tower, on the left side of the image. This facility was used for the referencing of the MM for the indirect MM integration approach.

The flight model production of the ATHENA optics will require two more such beamlines, and preparation of their accommodation has commenced. Space is at a premium at a facility like BESSY II, and advance planning is mandatory. A suitable area has been identified (figure 13), where the beamlines and the associated cleanrooms can be built. 


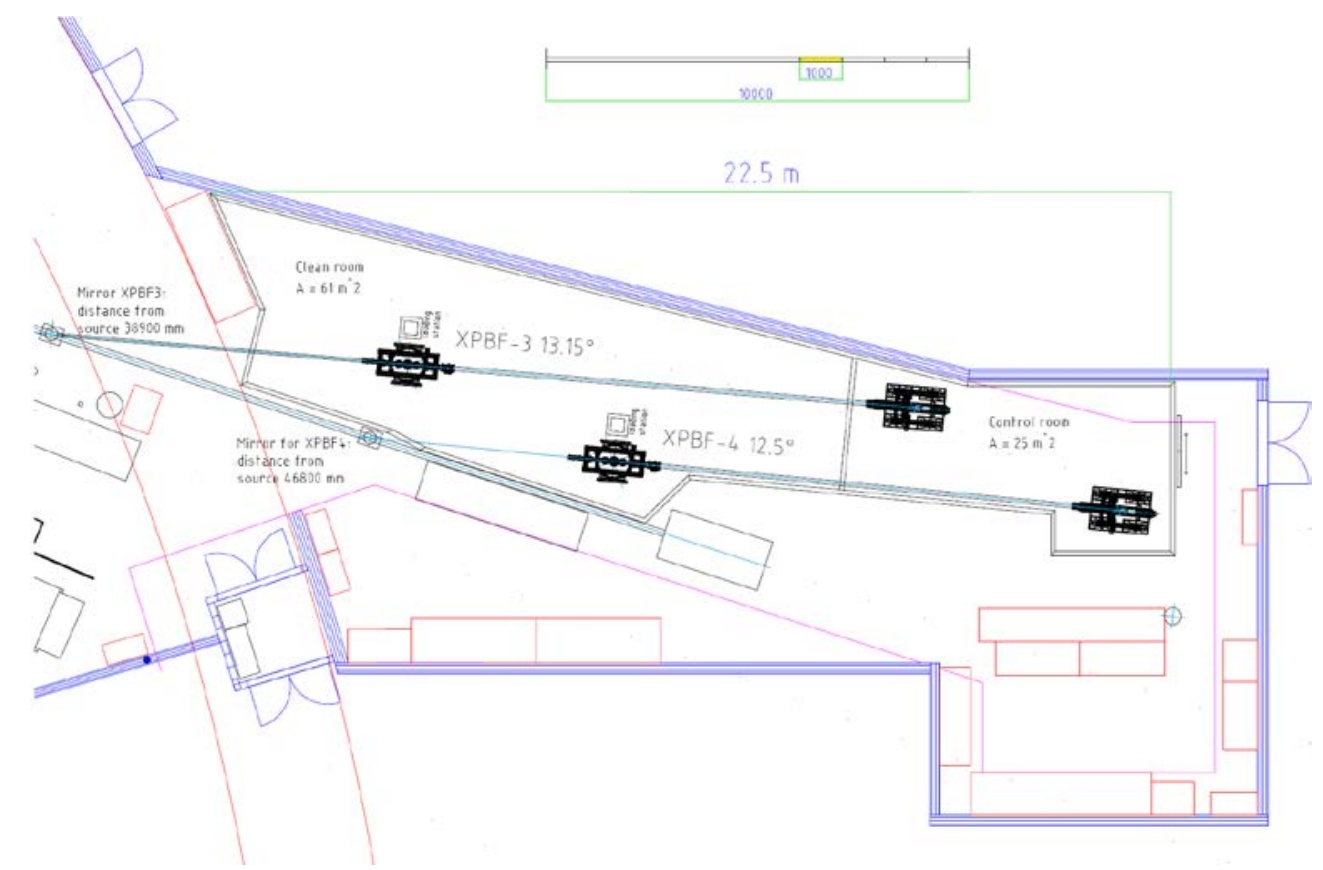

Figure 13: For the ATHENA flight programme two more synchrotron radiation beamlines, such as shown in figure 12, will be required. Planning of these additional beamlines has started, in order to secure the required floor space in the PTB laboratory. The flight production phase will extend over two years, and require the assembly of two MMs per day.

The imaging characteristics of mirror modules and assemblies of mirror modules will have to be characterised under Xray illumination, while being exposed to thermal loads. Special test equipment is being assembled at the PANTER facility, which will allow the simulation of many different thermal environments, including thermal gradients in all directions (figure 14).

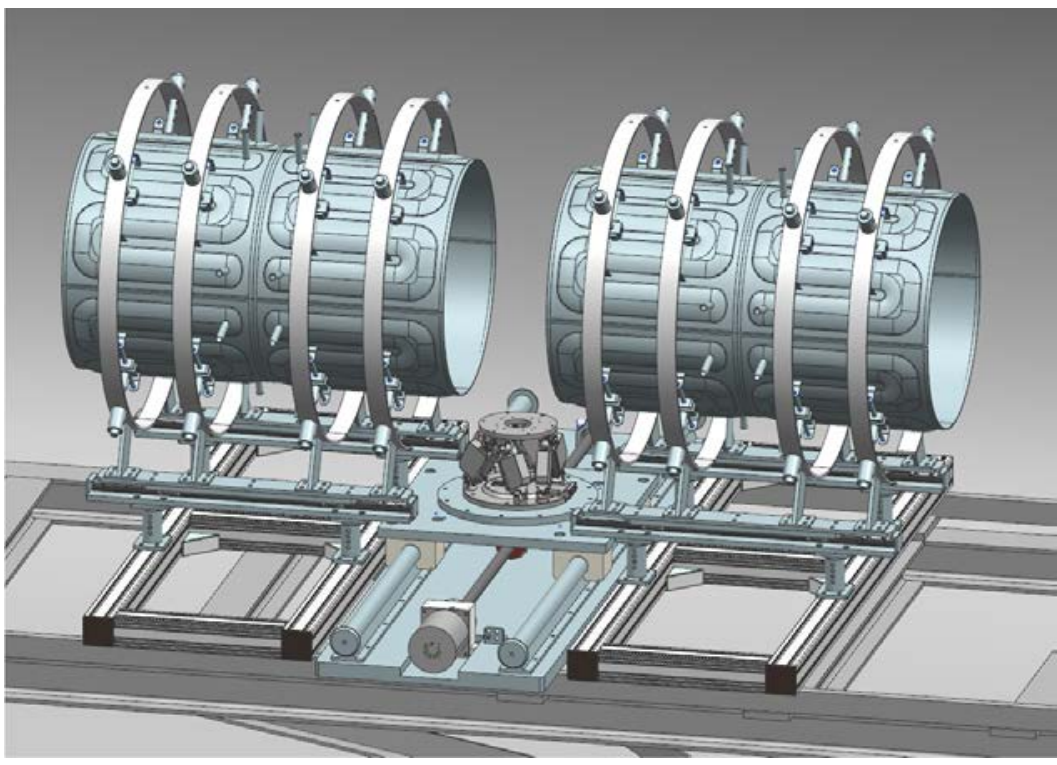

Figure 14: Thermal testing of MM assemblies under X-ray illumination will be required for ATHENA, to verify the impact of thermal gradients and temperature levels on the performance of the optics. For this purpose a sophisticated thermal test equipment 
is being installed at the PANTER facility by the Max-Planck-Institut für Extra-terrestrische Physik. The optics is positioned by the hexapod visible in the center of the figure, and the thermal environment is controlled by two cylindrical thermal baffles, each consisting of eight independent sectors. The whole assembly is positioned on the tip-tilt stage of the PANTER facility, permitting the observation of the X-ray image created by the optics under test.

\section{CONCLUSION}

A detailed Technology Development Plan (TDP) is in place, and is being continuously updated to follow the evolution of the mission and its technologies. The technology activities are mainly funded by the ESA Science Programme, and implemented in European industry and research entities.

We have shown in this paper that in the last year, as a result of this plan, progress was made on many areas. The mirror plate production has been scaled up, producing 2000 mirror mirror plates in 2017, feeding the further activities of the TDP. The coating process is being industrialised, and the development will continue into the next year, including the development of the coating recipe. Significant effort was and continues to be invested into the improvement of the angular resolution of the optics. On flight representative mirror modules the SPO technology has been migrated to the 12 $\mathrm{m}$ focal length required for ATHENA. While the initial sample was affected by the required equipment modifications, the first iteration could achieve a substantial improvement. Following the TDP, the activities in until the Mission Adoption Review (MAR) will focus on the further improvement of the angular resolution performance towards the requirements of ATHENA.

An important part of the TDP could be completed in the past year, with the successful demonstration of the integration of the mirror modules into a representative telescope structure, achieving the required co-alignment with good margins. Facilities required for the implementation of the ATHENA flight optics and its characterisation and verification are being planned.

The performance of the optics is paramount, but other factors are equally important to ensure mission adoption. The modularity of the Silicon Pore Optics (SPO), the reliance on proven materials, processes and equipment from the microelectronics and automotive industry, and the early consideration of the demands of the later flight model implementation facilitate the demonstration of the compliance to the ATHENA mission programmatic constraints, including cost and schedule.

\section{ACKNOWLEDGEMENTS}

The authors wish to thank the many contributors to the progress achieved on the preparation of the ATHENA optics technology. The joint effort of all individuals involved, and the support provided by their companies and institutions, is essential to the progress on the many fronts of development.

\section{REFERENCES}

[1] Nandra, P. et al, “ATHENA : The Advanced Telescope for High-Energy Astrophysics”, http://www.the-ATHENA-x-rayobservatory.eu/

[2] Ayre, M., et al, “ATHENA - System design and implementation for a next generation x-ray telescope”, Proc. of SPIE Vol. 9601, 96010L (2015)

[3] Ayre, M., et al, “ATHENA: system studies and optics accommodation”, Proc. SPIE 9905, 990526 (2016)

[4] Ayre, M., et al, “ATHENA - System design and implementation for a next generation x-ray telescope”, Proc. of SPIE Vol. 10397, 103970X-2 (2017)

[5] Beijersbergen, M. et al., "Development of x-ray pore optics: novel high-resolution silicon millipore optics for XEUS and ultralow mass glass micropore optics for imaging and timing", Proc. SPIE 5539, 104-115 (2004).

[6] Beijersbergen, M. et al., "Silicon pore optics: novel lightweight high-resolution X-ray optics developed for XEUS", Proc. SPIE 5488, 868-874 (2004). 
[7] Kraft, S. et al., "Development of modular high-performance pore optics for the XEUS x-ray telescope", Proc. SPIE 5900, 297-308 (2005).

[8] Günther, R. et al., "Production of silicon pore optics", Proc. SPIE 6266, 626619 (2006).

[9] Collon, M. J. et al., "Performance characterization of silicon pore optics", Proc. SPIE 6266, 62661T (2006).

[10] Collon, M. J. et al., "Metrology, integration, and performance verification of silicon pore optics in Wolter-I configuration", Proc. SPIE 6266, 626618 (2006).

[11] Graue, R. et al., "Assembling silicon pore optics into a modular structure", Proc. SPIE 6266, 62661U (2006).

[12] Wallace, K. et al, “Silicon pore optics development”, Proc. SPIE 7437, 7437 (2009).

[13] Kampf, D. et al., “Optical bench elements (petals) for IXO”, Proc. SPIE, 7437 (2009).

[14] Collon, M. J. et al, "Stacking of silicon pore optics for IXO”, Proc. SPIE, 7437 (2009).

[15] Ackermann, M et al, "Performance prediction and measurement of silicon pore optics”, Proc. SPIE, 7437 (2009).

[16] Vacanti, G, et al., “Silicon pore optics for astrophysical missions”, Proc. SPIE, 7732, 773240 (2010).

[17] Collon, M. J. et al, “Silicon Pore X-ray Optics for IXO”, Proc. SPIE 7732, 77321F (2010).

[18] Bavdaz, M., “ESA optics technology preparation for IXO”, Proc. SPIE 7732, 77321E (2010).

[19] Wille, E, et al, "Mass Production of Silicon Pore Optics for IXO and ATHENA", Proc. of SPIE 8147, 81470E1(2011)

[20] Collon, M, et al, "Design, Fabrication, and Characterization of Silicon Pore Optics for ATHENA/IXO”, Proc. of SPIE 8147, 81470D1(2011)

[21] Bavdaz, M. et al., “ESA led ATHENA/IXO optics development status”, Proc. of SPIE 8147, 81470C1(2011)

[22] Bavdaz, M, et al, "Silicon Pore Optics developments and status", Proc. of SPIE 8443, 844329(2012)

[23] Ackermann, M, et al, "Novel applications of Silicon Pore Optics technology”, Proc. of SPIE 8443, 84430V(2012)

[24] Bavdaz, M., et al, “X-ray optics developments at ESA”, Proc. of SPIE Vol. 8861, 88610L (2013)

[25] Collon, M., et al, “Aberration-free Silicon Pore X-ray Optics”, Proc. of SPIE Vol. 8861, 88610M (2013)

[26] Wille, E., et al, “Stray Light Baffling and Environmental Qualification of Silicon Pore Optics”, of SPIE Vol. 8861, 88611E (2013)

[27] Willingale, R. et al, "Science requirements and optimization of the silicon pore optics design for the ATHENA mirror", Proc. of SPIE Vol. 9144, 91442E (2014)

[28] Bavdaz, M. et al, "Preparing the optics technology to observe the hot universe”, Proc. of SPIE Vol. 9144, 91442F (2014)

[29] Collon, M. et al, "Making the ATHENA optics using Silicon Pore Optics”, Proc. of SPIE Vol. 9144, 91442G (2014)

[30] Wille, E. et al, “Qualification of Silicon Pore Optics”, Proc. of SPIE Vol. 9144, 91442H (2014)

[31] Bavdaz, M. et al, “The ATHENA Optics”, Proc. of SPIE Vol. 9603, 96030J (2015)

[32] Collon, M. et al, "Silicon Pore Optics development for ATHENA”, Proc. of SPIE Vol. 9603, 96030K (2015)

[33] Wille, E. et al, "Silicon Pore Optics Mirror Modules for Inner and Outer Radii”, Proc. of SPIE Vol. 9603, 96030L (2015)

[34] Vacanti, G., et al, "New ray-tracing capabilities for the development of Silicon Pore Optics”, Proc. of SPIE Vol. 9603, 96030G (2015)

[35] Della Monica Ferreira, D. et al., “Coating Optimisation for the ATHENA+ mission”, Proc. Of SPIE Vol.8861, 886112 (2013)

[36] Massahi S., et al, "Investigation of Photolithography Process on SPOs for the ATHENA Mission”, Proc. of SPIE Vol. 9603, 96030M (2015)

[37] Bavdaz, M., et al, “The ATHENA optics development”, Proc. SPIE 9905, 990527 (2016)

[38] Collon, M., et al, “Silicon pore optics for the ATHENA telescope”, Proc. SPIE 9905, 990528 (2016)

[39] Wille, E., et al, "Mass production of silicon pore optics for ATHENA”, Proc. SPIE 9905, 990529 (2016)

[40] Spiga, D., et al, "Simulation and modelling of silicon pore optics for the ATHENA x-ray telescope”, Proc. SPIE. 9905, 990550 (2016)

[41] Bavdaz, M., et al, “The ATHENA telescope and optics status”, Proc. of SPIE Vol. 10399, 103990B-1 (2017)

[42] Collon, M., “Development of ATHENA mirror modules”, Proc. of SPIE Vol. 10399, 103990C-1 (2017)

[43] Valsecchi, G., et al, "Optical integration of SPO mirror modules in the ATHENA telescope”, Proc. of SPIE Vol. 10399, 103990E-1 (2017)

[44] Vernani, D., et al, "Integration of the ATHENA mirror modules: development of indirect and X-ray direct AIT methods", Proc. of SPIE Vol. 10399, 103990F-1 (2017)

[45] Vacanti, G., et al, "Predicting Silicon Pore Optics”, Proc. of SPIE Vol. 10399, 103990M-1 (2017)

[46] Landgraf, B., et al, "Environmental testing of the ATHENA mirror modules”, Proc. of SPIE Vol. 10399, 103990G-1 (2017)

[47] Della Monica Ferreira, D. et al., "Design, development, and performance of X-ray mirror coatings for the ATHENA mission”, Proc. of SPIE Vol. 10399, 1039918-1 (2017) 
[48] Massahi, S., et al, "Industrialization of the mirror plate coatings for the ATHENA mission”, Proc. of SPIE Vol. 10399, 103991W-1 (2017)

[49] ISO, "Space systems - Definition of the Technology Readiness Levels (TRLs) and their criteria of assessment”, ISO 16290, The International Organization for Standardization (2013)

[50] O’Dell, S.L. and M. C. Weisskopf ,“Advanced X-ray astrophysics facility (AXAF): Calibration overview”, Proc. SPIE 3444 (1998) and references therein

[51] Jansen, F. et al., "XMM-Newton observatory", Astron. Astrophys. 365, L1-L6 (2001)

[52] William W. Craig, et al., "Fabrication of the NuSTAR Flight Optics”, Proc. of SPIE Vol. 8147, 81470H (2011)

[53] Krumrey, M. et al, “X-ray pencil beam facility for optics characterization”, Proc. SPIE 7732, 773240 (2010).

[54] Freyberg, M. et al., "Potential of the PANTER x-ray test facility for calibration of instrumentation for XEUS", Proc. SPIE 6266, 62663H (2006).

[55] Burwitz, V., et al, "In focus measurements of IXO type optics using the new PANTER X-ray test facility extension”, Proc. of SPIE Vol. 8861, 88611J (2013)

[56] Krumrey, M. et al, "New X-ray parallel beam facility XPBF 2.0 for the characterization of silicon pore optics”, Proc. SPIE. 9905, 99055N. (2016)

[57] Burwitz, V. et al., "Developing, testing, and calibrating the ATHENA optics at PANTER”, Proc. SPIE 10399, 103990O (2017)

[58] Fransen, S. et al, "Prediction of the mechanical environments of the load critical elements of the ATHENA spacecraft", Proc. 15th European Conference on Spacecraft Structures, Materials and Environmental Testing (2018) 